\title{
ROMANIAN PUBLIC-FUNDED RESEARCH AND DEVELOPMENT ACTIVITIES IN THE SPACE SECTOR
}

\author{
Nicolae-Mihail TONCEA *, Andrei STAN **, Octavian CRISTEA *** \\ *IAROM, Bucharest, **SPASTO CONSULTING, Bucharest, \\ $* * *$ BITNET CCSS, Cluj-Napoca, \\ iarom@xnet.ro, and_stan@yahoo.com,octavian.cristea@bitnet.info
}

\begin{abstract}
Romania achieved full membership within ESA (European Space Agency) in 2011 and is actually involved in several European flagship space programmes. The "National Strategy for Space and Related Fields" is a strategic project funded through the Romanian Space Technology and Advanced Research Program (STAR), which is implemented by a consortium coordinated by IAROM S.A. One of the project goals is to identify national space- related technological capabilities and possible niches for Romania within the European space industry, as well as to identify cooperation opportunities within the mandatory and optional ESA programs. This paper presents an overview of the areas of expertise covered by projects contracted in 2012 and 2013 in the framework of the national space research and development programme. The paper does not cover industrial space contracts since they contain sensitive information.
\end{abstract}

\section{Keywords: national strategy, space sector, Romania, ESA}

\section{Introduction}

Romania became ESA's $19^{\text {th }}$ Member State on 22 December 2011. This has led to a stepby-step integration within ESA programmes and projects. As part of this ongoing process, ROSA has developed five support tools generally called strategic projects.

The "National Strategy for Space and Related Fields - SNDS" is one of the strategic projects, which is jointly implemented by IAROM, SPASTO CONSULTING and BITNET CCSS [1].

The project's mission is to support the participation of Romanian organizations into mandatory and optional ESA programmes, including pre-qualification activities and adaptation to the ESA requirements [2]. This can be achieved by developing a medium to long-term strategy which will define the main objectives and directions that must be pursued for a sustainable development of the Romania's space sector.

\section{Analysis of contracted $R \& D$ space} projects in 2012 and 2013

The purpose of this analysis was to identify existing or potential national space-related competences. The results presented in this paper covers public-funded research and development space projects contracted in 2012 and 2013 within the framework of two national public-funded programs: "STAR" and "Partnerships in Priority S\&T Domains". The paper does not cover space contracts concluded by Romanian organizations with ESA and the European space industry since they contain sensitive information. 


\section{Evaluation methodology}

Relevant information for our analysis has been extracted from the following sources:

$\checkmark$ Public information (project websites, presentations during Romanian Space Week Conferences and similar events);

$\checkmark$ Documents made available by Romanian organization involved in space activities to the SNDS project consortium;

$\checkmark$ Informal discussions held with representatives from various research and industry entities (during workshops, ESA-Romania meetings, etc.)

For each identified space project, collected information has been organized using a synthetic sheet which contains the following information: project title, funding program, the coordinating organization and partners, brief description of the project objectives and estimated results, project's domain of expertise according to ESA programmes.

\subsection{Statistical analysis results}

We have identified and analysed a total number of 123 space projects. 108 projects have been funded through the
STAR programme C1 (2012) and C2 (2013) competitions which are coordinated by ROSA (Romanian Space Agency). From these 108 projects:

$\checkmark \quad 96$ of them are RDI (Research, Development and Innovation) projects;

$\checkmark \quad 7$ of them are CCTS (Competence Centre in Space Technologies) projects;

$\checkmark \quad 5$ of them are strategic projects.

Other 15 projects have been funded through the PCCA (Collaborative Projects on Applied Research) programme competitions which are coordinated by UEFISCDI (Executive Unit for Financing Higher Education, Research, Development and Innovation).

Table 1 presents information regarding the classification of the identified projects according to ESA programmes [3].

Table 1.Public-funded projects classification

\begin{tabular}{l|l|l|l|l}
\hline No. & ESA space programmes & 2012 & 2013 & TOTAL \\
\hline 1 & Science / Robotic exploration & 7 & 4 & 11 \\
\hline 2 & Earth observation (including GMES) & 12 & 12 & 24 \\
\hline 3 & Telecommunication and integrated & 1 & 1 & 2 \\
\hline 4 & Navigation (GNSS and Galileo) & 0 & 0 & 0 \\
\hline 5 & Human Space Flight & 0 & 1 & 1 \\
\hline 6 & Launchers & 6 & 2 & 8 \\
\hline 7 & Space Situational Awareness (SSA) & 3 & 2 & 5 \\
\hline 8 & Development and operation of micro-satellite & 3 & 2 & 5 \\
\hline 9 & $\begin{array}{l}\text { Development of technologies, } \\
\text { system, sensors and equipment for }\end{array}$ & 22 & 34 & 56 \\
\hline 10 & Other & 6 & 5 & 11 \\
\hline
\end{tabular}

Fig. 1 and Fig. 2 present a comparative analysis of space projects funded in 2012 and 2013. These figures clearly illustrate a pragmatic overview of the existing competences and interests among national organizations.

Several conclusions can be drawn from this statistical analysis.

$\checkmark \quad 65 \%$ of the total number of funded projects is related to the following 
domains: Earth Observation (20\%) and Development of technologies, systems, sensorsand equipment for space applications (45\%).

$\checkmark$ There are no funded projects related to Navigation (GNSS and Galileo). To some extent, the situation is the same on
Telecommunication and Human space flight fields, having identified a total of 3 funded projects.

11 projects have been identified in the Science field, but there is no project in the field of Robotic exploration.

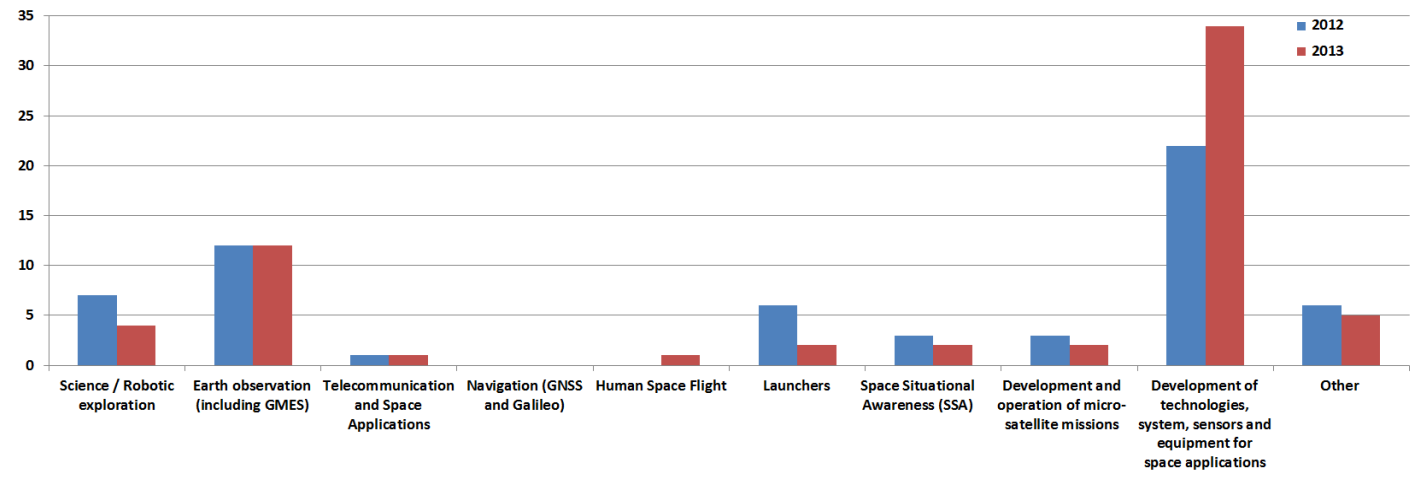

Figure 1: Classification of contracted space projects according to ESA programmes.

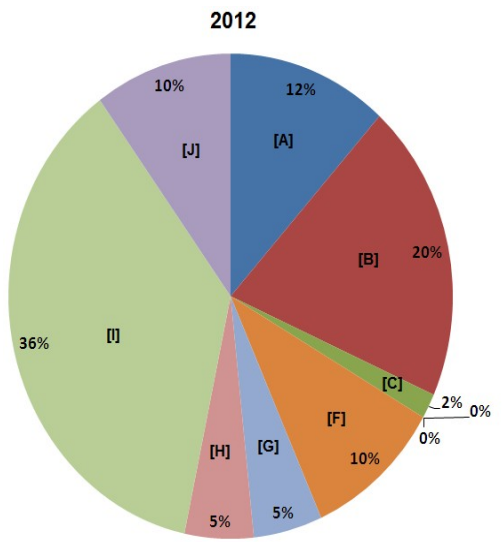
Comparative analysis for 2012 and 2013

Figure 2: Percentage of funded projects according to ESA programmes. Comparative analysis for 2012 and 2013

Other relevant information extracted from our analysis: 88 national entities have contracted at least one project as prime or sub-contractors (partners), from which:

$\checkmark 46$ entities (52\%) are from the public sector (institutes, universities, agencies, research centers, etc.);

$\checkmark \quad 42$ entities $(48 \%)$ are from the private sector (companies including SMEs). Figure 3 illustrates an analysis of the Romanian entities involved in space contracts (research organizations vs. companies) and their geographical distribution.

The analysis for 2012 and 2013 reveals that:

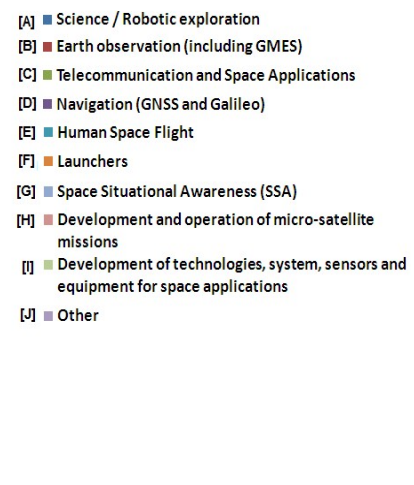

[B] E. Earth observation (including GMST) [C] 1 Telecommunication and Space Applications [H] $₫$ Development and operation of micro-satellite Development of technologies, system, sensors and equipment for space applications
[G]

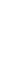


space related ESA programs to which Romania is contributing (for instance GNSS and Galileo).

Mismatch between Romanian project proposals addressing space technologies

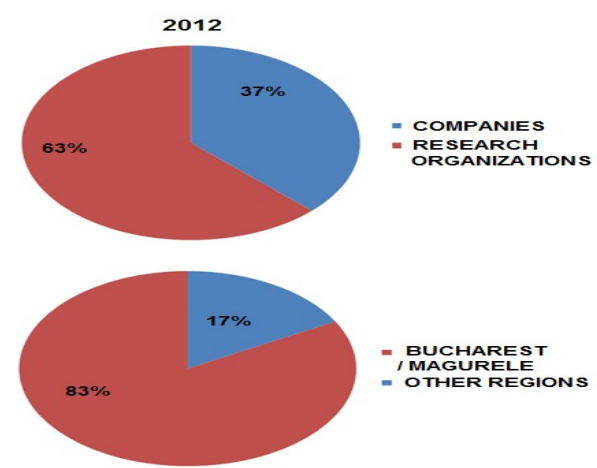

and the ESA "Compendium of Potential Generic Technology Activities" [4] (which raises questions about potential space industry niches for Romania).

Figure 3: Percentage of participating Romanian entities to the national space programme; Research organization vs. companies. Entities from Bucharest area vs. entities from other regions

\section{Conclusions}

Romania has potential for developing space related European industrial niches in the field of technology:

$\checkmark$ Software development for various space systems;

$\checkmark$ Development of components, subassemblies, structure $\mathrm{s}$ for small launchers and satellites;

$\checkmark$ Development of scientific instruments/ sensors on-board for various space missions;

$\checkmark \quad$ Development of nanosatellites.

Service provision represents another potential niche for the Romanian space industry, mainly regarding:
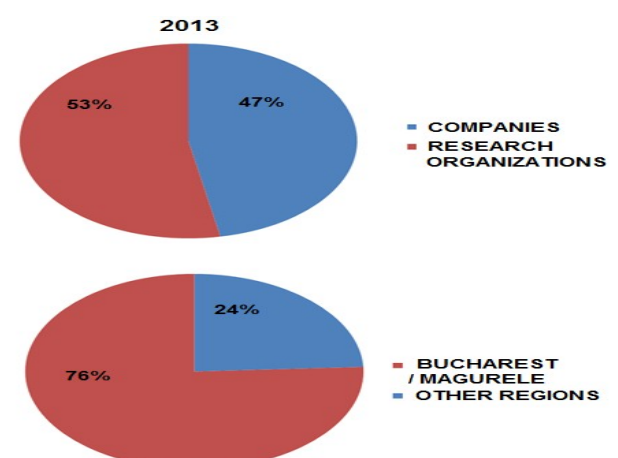

\section{References}

[1] IAROM (2015), National Strategy for Space and Related Fields - SNDS, Official project website, [Online]. Available: http://snds.iarom.ro/en/

[2] N. Toncea, A. Stan, O. Cristea, Towards a national strategy in support of developing Romanian space capabilities, Proceedings of the $19^{\text {th }}$ International Scientific Conference KBO (Knowledge-Based Organization), Sibiu, 13-15 June 2013, pp. 124-129, ISSN 1843-6722.

[3] ESA (2015), ESA 2015 budget - classification by domains, [Online]. Available: http://www.esa.int/About_Us/Welcome_to_ESA/Funding

[4] ESA / ESTEC (2015), GSTP-6 Element 1-Compendium of Potential Generic Technology Activities (SD7) / Activities intended to be initiated in 2014, TEC-SGT/2013-008/NP, [Online]. Available: http://emits.sso.esa.int/emits-doc/ESTEC/GSTP6_E1_List_ of_TechnologyActivities_2014.pdf 